\title{
ESTADO FÍSICO DO MEIO DE CULTURA NA PROPAGAÇÃO IN VITRO DE BROMELIACEAE
}

\section{THE PHYSICAL STATE OF THE CULTURE MEDIUM ON THE BEHAVIOR IN VITRO OF BROMELIACEAE}

\author{
Liana Hilda Golin MENGARDA ${ }^{1}$ \\ Luciano POVOAS ${ }^{1}$ \\ Clayton DEBIASI ${ }^{2}$ \\ Rosete PESCADOR ${ }^{3}$
}

\section{RESUMO}

O objetivo deste estudo foi avaliar o efeito do estado físico do meio de cultura sobre o comportamento in vitro de Neoregelia cruenta, Tillandsia stricta, Vriesea gigantea, V. guttata e V. incurvata. Brotos micropropagados foram cultivados em meio de cultura MS, com $30 \mathrm{~g}$ de sacarose, $2,5 \mathrm{mg} \mathrm{dm}^{-3}$ BAP, e $0,5 \mathrm{mg} \mathrm{dm}^{-3}$ ANA estabelecendo os seguintes tratamentos: T1-semi-sólido com $7 \mathrm{~g}$ de ágar; T2- líquido estático; T3- líquido sob-agitação a $90 \mathrm{rpm}$; e T4- líquido estático com ponte de papel filtro. Após 30 dias de cultivo, a utilização do meio de cultura líquido estático apresentou melhores resultados em relação à taxa média proliferativa em todas as espécies $\left(9,4\right.$ brotos explante ${ }^{-1}$ em $N$.cruenta, 5,6 em $T$. stricta, 11,5 em V. gigantea, 9,2 em V. guttata e 3,9 em V. incurvata). Em relação à altura média dos brotos, destacou-se para $N$. cruenta o meio líquido sob agitação $(2,83 \mathrm{~cm})$, para $T$. stricta e $V$. incurvata o semi-sólido $(1,76 \mathrm{~cm}$ e $2,02 \mathrm{~cm}$, respectivamente) e para $V$. gigantea e $V$. guttata o líquido estático $(0,61 \mathrm{~cm}$ e $1,48 \mathrm{~cm}$, respectivamente). A utilização de meio de cultura MS líquido estático mostrou-se como sendo o mais adequado para o cultivo in vitro das espécies de bromélias estudadas.

Palavras-chave: micropropagação; conservação da biodiversidade; bromélias ornamentais.

\begin{abstract}
The objective of this study was to evaluate the effect of the physical state of the culture medium on the behavior in vitro of the bromeliaceas Neoregelia cruenta, Tillandsia stricta, Vriesea gigantea, V. guttata e V. incurvata. Micropropagated shoots had been cultivated in culture medium MS, with $30 \mathrm{~g}$ sucrose, $2,5 \mathrm{mg} \mathrm{dm}^{-3} \mathrm{BAP}$, and $0,5 \mathrm{mg} \mathrm{dm}^{-3}$ ANA, establishing the treatments: T1- half-solid with $7 \mathrm{~g}$ agar; T2- static liquid; T3- liquid under-agitation of $90 \mathrm{rpm}$; and T4static liquid with bridge of paper filter. After 30 days, the use of static way of liquid culture presented better results in relation of proliferative average rate in all the species (9.4 shoots in N. cruenta, 5.6 in T. stricta, 11.5 in V. gigantea, 9.2 in V. guttata and 3.9 in $\mathrm{V}$. incurvata). In relation the average height of the shoots, was distinguished for $N$. cruenta the liquid under-agitation $(2.83 \mathrm{~cm}), T$. stricta and $V$. incurvata the semisolid $(1.76 \mathrm{~cm}$ and $2.02 \mathrm{~cm}$, respectively) and $V$. gigantea and $V$. guttata the static liquid $(0.61 \mathrm{~cm}$ and $1.48 \mathrm{~cm}$, respectively). The use of medium MS static liquid was more suitable for in vitro culture of bromeliads species studied.
\end{abstract}

Key-words: micropropagation; biodiversity conservation; ornamental bromeliads.

\footnotetext{
${ }^{1}$ Biólogo (a), Universidade Regional de Blumenau. Laboratório de Biotecnologia e Micropropagação Vegetal, Universidasde Regional de Blumenau (FURB), Blumenau, Santa Catarina, Brasil. E-mail: liana_ya@yahoo.com.br. e-mail: povoasbio@yahoo.com.br ${ }^{2} \mathrm{Eng}^{\circ} \mathrm{Agr}^{\circ}, \mathrm{Dr}^{\circ} \mathrm{em}$ Agronomia, Universidade Estadual Paulista Júlio de Mesquita Filho. Laboratório de Micropropagação, Universidade Estadual de Paulista "Júlio de Mesquita Filho"(UNESP), Botucatu, São Paulo, Brasil. E-mail: claytondebiasi@gmail.com.

${ }^{3} \mathrm{Eng}^{\mathrm{a}}$. Agr ${ }^{\mathrm{a}}, \mathrm{Dr}^{\mathrm{a}}$ em Botânica, Universidade Regional de Blumenau. Laboratório de Biotecnologia Micropropagação Vegetal, DCN/T-123, Universidade Regional de Blumenau(FURB), Rua Antônio Haffner, 455, apto 204, Bairro Asilo, CEP: 89.036-640, Blumenau, Santa Catarina, Brasil. E-mail: rosetep@furb.br.
} 
MENGARDA, L.H.G. et al. Estado físico do meio de cultura na propagação...

\section{INTRODUÇÃO}

A família Bromeliaceae é representada por aproximadamente 3.086 espécies distribuídas em 58 gêneros (Luther, 2006), cuja ocorrência vai desde o sul da América do Norte até a Patagônia (Wanderley et al., 2007). Possui grande diversidade nas florestas pluviais, sendo seu endemismo marcante, tem importância econômica em muitos países, seja como alimento, planta ornamental ou fornecedora de substâncias de interesse industrial (Reitz, 1983; Oliveira, 2004).

A importância das bromélias como plantas ornamentais é o principal fator que leva várias espécies nativas a categoria de ameaçadas de extinção, pois muitas vezes são foco de extrativismo (Reitz, 1983). Em função disto, é crescente o interesse na aplicação de técnicas de micropropagação na conservação destas espécies, permitindo a exploração eficiente das mesmas, em comparação com a multiplicação vegetativa natural, considerada lenta e de baixo rendimento em termos de número de mudas produzidas (Droste et al., 2005).

O estabelecimento e a propagação in vitro de uma espécie estão submetidos aos mais diversos fatores. Entre os mais importantes citamse os nutrientes minerais e reguladores de crescimento no meio de cultura que, em combinação com outros fatores, como o estado físico, proporciona a propagação efetiva de cada espécie (Kozay et al., 1997; Fortes \& Pereira, 2001). A alteração do estado físico do meio de cultura modifica a resistência física e de contato dos explantes com o meio, podendo influenciar no desenvolvimento de plântulas in vitro (Chen \& Ziv, 2001). Assim, o maior contato dos explantes com meio, que acontece nos cultivos em meio líquido, pode aumentar a absorção de água e nutrientes quando comparado ao meio semi-sólido, favorecendo a taxa de assimilação de nutrientes, altura e multiplicação de brotos e, ainda, acúmulo de massa seca (Pereira \& Fortes, 2003). O estado físico do meio de cultura, portanto, pode estar relacionado ao desempenho assimilatório das plantas durante o período de cultivo do material vegetal (Ziv, 1995). Sendo assim, o estabelecimento de protocolos de micropropagação requer a aplicação de vários ensaios, a fim de estabelecer o melhor meio de cultura para determinada espécie, já que, de acordo com as características genéticas, cada uma pode apresentar respostas diferentes sob as mesmas condições de cultivo (Ziv, 1995; Fortes \& Pereira, 2001).

O estado físico do meio de cultura pode ser alterado pela exclusão ou adição de ágar, modificando, assim, a disponibilidade de água, nutrientes e dos reguladores de crescimento (Grattapaglia \& Machado, 1998). A utilização de meios de cultura líquidos, ou seja, sem a adição do ágar, tem proporcionado igual ou até maior eficiência para diversas espécies vegetais, e neste sentido, alguns estudos relacionados com o estado físico do meio de cultura em bromeliáceas tem sido realizados, principalmente com abacaxizeiro (Escalona et al., 1999; Feuser et al., 2001; Oliveira et al., 2007), com o objetivo de facilitar o preparo e manipulação da cultura e, especialmente de baratear os custos deste sistema de propagação. No entanto, poucas espécies de bromélias apresentam protocolo estabelecido e otimizado para micropropagação. Sendo assim, o objetivo deste trabalho foi verificar o efeito do estado físico do meio de cultura na micropropagação de cinco espécies nativas de bromeliáceas, endêmicas da Mata Atlântica e com potencial ornamental, por meio da avaliação da taxa de proliferação e da altura dos brotos formados.

\section{MATERIAL E MÉTODOS}

Exemplares de Neoregelia cruenta, Tillandsia stricta, Vriesea gigantea, Vriesea guttata e Vriesea incurvata, estabelecidos in vitro, mantidos em meio de cultura MS 0 semi-sólido (desprovidos de reguladores de crescimento) e conservados em câmara germinativa, forneceram os explantes iniciais (brotos com $\pm 1,0 \mathrm{~cm}$ de altura). Os explantes (dez explantes tratamento ${ }^{-1}$ ) por tratamento foram transferidos para tubos de ensaio $\left(0,05 \mathrm{dm}^{3}\right)$, contendo $0,01 \mathrm{dm}^{3}$ de meio de cultura MS (Murashige \& Skoog, 1962), suplementados com sacarose $(30 \mathrm{~g})$, reguladores de crescimento 6benzilaminopurina BAP $\left(2,5 \mathrm{mg} \mathrm{dm}^{-3}\right)$ e ácido naftalenoacético ANA $\left(0,5 \mathrm{mg} \mathrm{dm}^{-3}\right)$, e $\mathrm{pH}$ ajustado para 5,8 . Tais reguladores e concentrações foram utilizadas de acordo com ensaios preliminares, não publicados, nos quais tal protocolo se mostrou adequado para multiplicação de bromeliáceas in vitro. Foram estabelecidos os tratamentos: T1semi-solidificado com $7 \mathrm{~g}$ ágar; T2- líquido estático; T3- líquido sob agitação rotatória a 90 rpm; e T4líquido estático com ponte de papel filtro. $\mathrm{O}$ material foi mantido em sala de crescimento com fotoperíodo de $16 \mathrm{~h} \mathrm{luz} \mathrm{dia}{ }^{-1}\left(50 u \mathrm{~mol} \mathrm{~m} \mathrm{~s}^{-1}\right)$, e temperatura de $25 \pm 2{ }^{\circ} \mathrm{C}$.

As características biométricas avaliadas após 30 dias de cultivo foram a taxa média proliferativa por explante (número médio de brotações formadas) e a altura média dos brotos, além da ocorrência de hiperidricidade nos tecidos. $\mathrm{O}$ experimento foi estabelecido em DIC (delineado inteiramente casualizado), com 10 repetições por tratamento (cada repetição representada por um explante). A interpretação dos dados foi baseada em análise de variância (ANAVA) e teste de Tukey ao nível de $5 \%$ de probabilidade de erro.

\section{RESULTADOS E DISCUSSÃO}

A taxa média proliferativa por explante, após 30 dias de cultivo in vitro, variou significativamente conforme o estado físico do meio de cultura em todas as espécies estudadas (Tabela 1; Figura 1). 
MENGARDA, L.H.G. et al. Estado físico do meio de cultura na propagação...

TABELA 1 - Taxa média proliferativa in vitro (brotos explante ${ }^{-1}$ ) de $N$. cruenta, $T$. stricta, V. gigantea, V. guttata e $V$. incurvata, aos 30 dias de cultivo, nos diferentes meios de cultura.

\begin{tabular}{cccccc}
\hline Tratamentos & $\begin{array}{c}\text { Neoregelia } \\
\text { cruenta }\end{array}$ & $\begin{array}{c}\text { Tillandsia } \\
\text { stricta }\end{array}$ & $\begin{array}{c}\text { Vriesea } \\
\text { gigantea }\end{array}$ & $\begin{array}{c}\text { Vriesea } \\
\text { guttata }\end{array}$ & $\begin{array}{c}\text { Vriesea } \\
\text { incurvata }\end{array}$ \\
\hline T1 & $1,1 \mathrm{c}$ & $1,0 \mathrm{~b}$ & $4,3 \mathrm{~b}$ & $2,9 \mathrm{~b}$ & $1,7 \mathrm{~b}$ \\
T2 & $9,4 \mathrm{a}$ & $5,6 \mathrm{a}$ & $11,5 \mathrm{a}$ & $9,2 \mathrm{a}$ & $3,9 \mathrm{a}$ \\
T3 & $3,5 \mathrm{~b}$ & $0,0 \mathrm{c}$ & $5,2 \mathrm{~b}$ & $0,0 \mathrm{c}$ & $0,3 \mathrm{c}$ \\
T4 & $2,0 \mathrm{bc}$ & $0,7 \mathrm{bc}$ & $4,9 \mathrm{~b}$ & $5,1 \mathrm{~b}$ & $0,8 \mathrm{bc}$ \\
\hline CV $\%$ & 39,04 & 39,28 & 46,65 & 52,82 & 59,62 \\
\hline DMS & 1,88 & 0,87 & 3,57 & 2,75 & 1,20 \\
\hline
\end{tabular}

$\mathrm{T} 1=$ meio semi-solidificado com $7 \mathrm{~g} \mathrm{dm}^{-3}$ de ágar; $\mathrm{T} 2=$ meio líquido estático; T3= meio líquido sob agitação rotatória a $90 \mathrm{rpm}$; T4= meio líquido estático com ponte de papel filtro). Letras referem-se à diferença entre os tratamentos. Médias seguidas da mesma letra não diferem entre si pelo teste de Tukey $(p<0,05), n=10 . C V \%=$ coeficiente de variação; DMS = diferença mínima significativa.

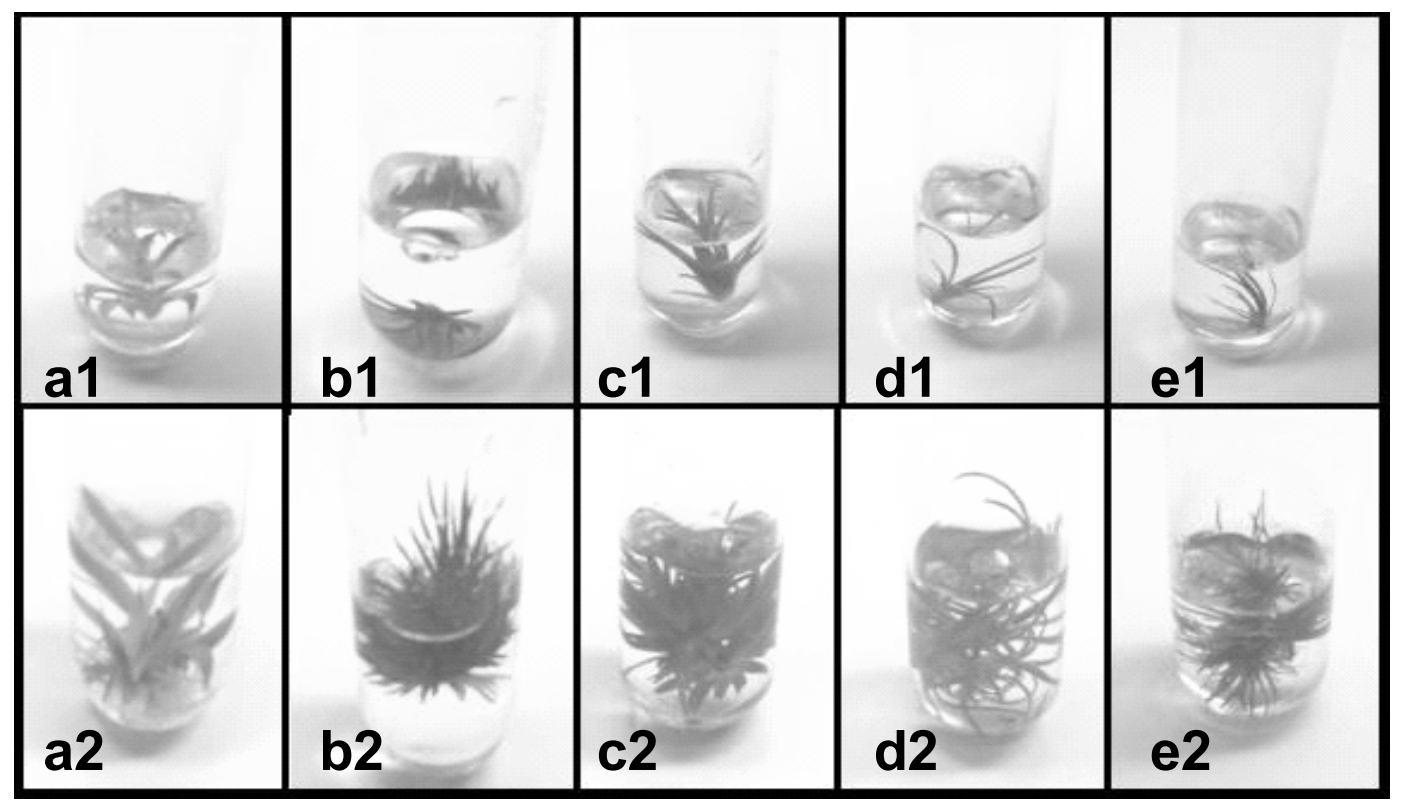

FIGURA 1 - Explantes de Bromeliaceae cultivados no tratamento 2 (líquido estático), sendo 1 representando o dia 0 , e 2 representando o mesmo tratamento após 30 dias. a- Neoregelia cruenta. bTillandsia stricta. c- Vriesea gigantea. d- Vriesea guttata. e- Vriesea incurvata.

Para as bromélias do presente estudo, observou-se que, de modo geral, o tratamento T2 (meio líquido estático) foi o que proporcionou as maiores taxas proliferativas. Assim, observou-se para $N$. cruenta o número médio de 9,4 brotos explante ${ }^{-1}$, bem como 5,6, para $T$. stricta, o valor de 11,5 para $V$. gigantea; 9,2 para $V$. guttata e por último 3,9 para $V$. Incurvata, todos significativamente superiores aos números médios obtidos nos demais tratamentos para cada espécie.

\section{Culturas como aspargo (Asparagus} officinalis) e gengibre (Zingiber officinale), têm preferências pelo meio de cultura semi-sólido para seu estabelecimento e propagação in vitro, enquanto as bromélias, de forma geral, respondem melhor ao meio de cultura líquido (Murashige, 1974).

Ainda com relação aos representantes da família das bromeliáceas, e corroborando com os resultados do presente trabalho, Feuser et al. (2001), micropropagando abacaxizeiro
(Bromeliaceae) observaram resultados mais eficientes com a utilização de meio de cultura líquido e Oliveira et al. (2007), também verificaram melhores resultados quanto à multiplicação in vitro de abacaxi ornamental foi feita também em meio líquido.

Por outro lado, o uso de meio semisólido pode não ser tão satisfatório para estas bromeliaceas. Barboza et al. (2004) destacam que a utilização do meio de cultura semi-sólido na propagação in vitro de dois genótipos de abacaxizeiro (Ananas comosus), a cultivar Smooth Cayenne e o híbrido PExSC-52, apesar de promover taxas proliferativas satisfatórias, levou a formação de aglomerados de gemas e de minúsculos brotos, o que dificulta o trabalho de subcultivo e individualização.

Os resultados referentes à taxa média proliferativa obtidas para $N$. cruenta, no presente estudo, foram melhores estatisticamente em dois tratamentos com meio de cultura líquido (T2- meio 
MENGARDA, L.H.G. et al. Estado físico do meio de cultura na propagação...

líquido estático, com 9,2 brotos explante ${ }^{-1}$, e T3líquido sob agitação rotatória a $90 \mathrm{rpm}$, com 3,5 brotos explante $\left.{ }^{-1}\right)$. Já 0 tratamento $T 1$, que representava o meio de cultura semi-sólidificado com $7 \mathrm{~g} \mathrm{dm}^{-3}$ ágar, induziu a menor média de produção de novos brotos nesta espécie $(1,1$ brotos explante $^{-1}$ ), não diferindo estatisticamente do T4líquido estático com ponte de papel filtro $(2,0$ brotos explante $^{-1}$ ), conforme pode ser observado na Tabela 1.

Borges et al. (2001) descreveram que gemas laterais de Ananas porteanus cultivadas in vitro em meio de cultura MS líquido, suplementado com $1,0 \mathrm{mg} \mathrm{dm}^{-3}$ de BAP e $0,5 \mathrm{mg} \mathrm{dm}^{-3}$ ANA, após 60 dias de cultivo, apresentaram taxa média de proliferação de 13 novos brotos explante ${ }^{-1}$, média significativamente superior àquelas obtidas em meio de cultura semi-solidificado suplementado com a mesma concentração de reguladores. Rech Filho et al. (2008) também observaram o melhor resultado quanto à taxa proliferativa ao utilizar meio de cultura MS líquido em culturas nodulares de Vriesea reitzii objetivando a formação de novos brotos.

Alvard et al. (1993) avaliaram o estado físico do meio de cultura (líquido e sólido), na multiplicação in vitro de bananeira em seis tratamentos: 1- semi-solidificado com ágar; 2líquido com imersão das plantas; 3- líquido com suporte de papel; 4- líquido com imersão parcial das plantas; 5- líquido com aeração de borbulhas e; 6líquido com imersão temporária - 20 min a cada 2 h. Após 20 dias de cultivo, três grupos estatisticamente diferenciados se destacaram: o primeiro grupo, formado pelos meios de cultura líquido com imersão das plantas e líquido com suporte de papel, nos quais praticamente não houve proliferação; o segundo grupo, pelos meios de cultura semi-solidificado com ágar e líquido com aeração de borbulhas, nos quais observaram taxas de proliferação média de 2,2 a 3,1 brotos e; o terceiro grupo, pelo meio de cultura líquido com imersão temporária - 20 min a cada $2 \mathrm{~h}$, o qual apresentou média superior de 5 brotos explante ${ }^{-1}$. Já Prasad \& Gupta (2006) cultivaram brotos laterais de gladíolo (Gladiolus hybridus Hort. Cv. Hedding Bouquet) em meios de cultura semi-sólido (ágar), líquido com suporte de membrana, e líquido com suporte de espuma, todos adicionados com 1,0 mg $\mathrm{dm}^{-3}$ de ANA e $2,0 \mathrm{mg} \mathrm{dm}^{-3}$ de BAP e obtiveram a melhor resposta a partir da utilização do meio de cultura líquido com suporte de membrana, com média de 33,15 brotos explante ${ }^{-1}$.

Segundo Alvard et al. (1993) e Grattapaglia \& Machado (1998), normalmente os cultivos in vitro realizados em meios de cultura líquidos requerem suporte ou agitação para o fornecimento de oxigênio necessário ao metabolismo do explante, garantindo a divisão e a diferenciação para formação de brotos. No entanto, os protocolos variam de acordo com a espécie e o tipo de explante. No presente trabalho, os resultados observados para todas as espécies estudadas apontam 0 meio de cultura líquido estático como sendo aquele que proporcionou melhores resultados em termos de proliferação (Tabela 1). A imersão constante dos explantes no meio de cultura parece não afetar negativamente o comportamento in vitro das espécies estudadas. Observou-se, ainda, que $T$. stricta, V. guttata e V. incurvata, quando cultivadas no meio líquido sob agitação rotatória a 90 rpm (T3), praticamente não proliferaram, apresentando as menores médias, estatisticamente diferente dos demais tratamentos.

De acordo com os resultados apresentados, ficou evidente que a utilização de meio de cultura de consistência líquida sob condição estática proporcionou maior taxa de multiplicação. Este resultado tem suporte nos trabalhos de Levin et al. (1997) e Chen \& Ziv (2001), os quais apontam que no meio de cultura líquido ocorre aumento da disponibilidade de água e nutrientes, não existindo resistência física à difusão quando comparado ao que ocorre nos meios de cultura de consistência semi-sólida. Caldas et al. (1990) e Ziv (1995) afirmam que o maior contato dos explantes com o meio de cultura faz com que a taxa de assimilação de nutrientes pelo material vegetal, durante o cultivo in vitro, seja favorecida, enquanto que o meio semi-solidificado tem a propriedade de impor restrições à velocidade de difusão de nutrientes, podendo até causar deficiência em alguns casos.

Verificaram-se resultados pouco expressivos em praticamente todas as espécies estudadas, quando cultivadas em meio semisolidificado com $7 \mathrm{~g} \mathrm{dm}^{-3}$ ágar (Tratamento T1). 0 ágar, utilizado como agente gelificante no meio de cultura age sobre o potencial mátrico, alterando a disponibilidade de água, nutrientes e reguladores de crescimento, modificando assim a condição física do meio de cultura (Grattapaglia \& Machado, 1998). Segundo Caldas et al. (1990), é possível que as concentrações ótimas de sais num meio semisolidificado devam ser mais elevadas que aquelas ótimas em um meio líquido, além de estarem impondo restrições físicas à velocidade de difusão de nutrientes. Assim, a adição ou exclusão deste componente ao meio de cultura, pode representar efeitos significativos que estarão atuando de forma diferenciada sobre o desenvolvimento vegetal.

Em relação à altura média dos brotos formados, observou-se pouca variação entre os tratamentos dentro de cada espécie estudada (Tabela 2).

O tratamento T1 (semi-solidificado com $7 \mathrm{~g} \mathrm{dm}^{-3}$ de ágar), que apresentou menor taxa proliferativa quando comparado com os demais tratamentos, no parâmetro altura média dos brotos, induziu médias superiores em três das cinco espécies em estudo ( $T$. stricta, com $1,76 \mathrm{~cm}$; $V$. guttata, com 1,48 cm; e $V$. incurvata, com $2,02 \mathrm{~cm}$ de altura), porém não havendo, para estas três espécies, diferença estatística entre $\mathrm{T} 1$ e pelo menos um dos demais tratamentos. Segundo Debiasi et al. (2002), a média proliferativa e o tamanho dos brotos in vitro são parâmetros inversamente proporcionais, ou seja, quanto maior o número de brotos formados em um explante, 
MENGARDA, L.H.G. et al. Estado físico do meio de cultura na propagação...

menor será o seu tamanho, o que pode explicar os resultados obtidos no presente trabalho.

Para a espécie $V$. gigantea não houve diferença estatística quanto a altura do brotos entre os tratamentos testados. Já $N$. cruenta teve maior crescimento quando cultivadas no tratamento T2 (meio líquidos estático) não diferindo estatísticamente de T1 e T3.

TABELA 2 - Altura média (cm) dos brotos formados in vitro de N. cruenta, T. stricta, V. gigantea, V. guttata e $V$. incurvata, aos 30 dias de cultivo, nos diferentes meios de cultura.

\begin{tabular}{cccccc}
\hline Tratamentos & $\begin{array}{c}\text { Neoregelia } \\
\text { cruenta }\end{array}$ & $\begin{array}{c}\text { Tillandsia } \\
\text { Stricta }\end{array}$ & $\begin{array}{c}\text { Vriesea } \\
\text { gigantea }\end{array}$ & $\begin{array}{c}\text { Vriesea } \\
\text { guttata }\end{array}$ & $\begin{array}{c}\text { Vriesea } \\
\text { incurvata }\end{array}$ \\
\hline T1 & $1,7 \mathrm{ab}$ & $1,76 \mathrm{a}$ & $0,37 \mathrm{ab}$ & $1,48 \mathrm{ab}$ & $2,02 \mathrm{a}$ \\
$\mathrm{T} 2$ & $2,83 \mathrm{a}$ & $1,51 \mathrm{ab}$ & $0,61 \mathrm{ab}$ & $1,3 \mathrm{ab}$ & $1,56 \mathrm{ab}$ \\
$\mathrm{T} 3$ & $2,07 \mathrm{ab}$ & $1,1 \mathrm{~b}$ & $0,27 \mathrm{ab}$ & $1,2 \mathrm{ab}$ & $1,28 \mathrm{~b}$ \\
$\mathrm{~T} 4$ & $1,57 \mathrm{~b}$ & $1,47 \mathrm{ab}$ & $0,41 \mathrm{ab}$ & $1,35 \mathrm{ab}$ & $1,77 \mathrm{ab}$ \\
\hline CV $\%$ & 48,22 & 29,33 & 76,56 & 55,05 & 30,02 \\
\hline DMS & 1,19 & 0,52 & 0,39 & 0,88 & 0,60 \\
\hline
\end{tabular}

T1= meio semi-solidificado com $7 \mathrm{~g} \mathrm{dm}^{-3}$ de ágar; T2= meio líquido estático; T3= meio líquido sob agitação rotatória a 90 rpm; $\mathrm{T} 4=$ meio líquido estático com ponte de papel filtro). Letras referem-se à diferença entre os tratamentos. Médias seguidas da mesma letra não diferem entre si pelo teste de Tukey $(p<0,05), n=10$. CV\% = coeficiente de variação; DMS = diferença mínima significativa.

Segundo Carneiro et al. (1998), variações na taxa de multiplicação, e diferentes padrões de crescimento, podem ser atribuídos ao genótipo, sugerindo que as diferenças dos genótipos estudados no presente trabalho é que levaram às variações obtidas quanto à resposta as condições físicas do meio de cultura. Pode-se dizer, ainda, que o uso de um meio de cultura apropriado e ajustado para cada espécie é necessário para que se obtenha uma condição na qual o metabolismo das células vegetais em cultivo in vitro, estabeleça padrões que levem à diferenciação de tecidos, acompanhado também pelo crescimento dos mesmos.

Chen \& Ziv (2001) apontam que, apesar das vantagens da utilização de meios de cultura líquidos sobre os semi-solidificados, o meio líquido pode não ser adequado para determinadas espécies, uma vez que pode induzir a hiperidricidade das brotações. Tal fato pode ser atribuído ao provável aumento na absorção dos nutrientes e reguladores do meio que ocorre não apenas através da base, mas por toda sua superfície. A hiperidricidade pode afetar drasticamente o processo de aclimatação de mudas micropropagadas in vitro, pois estas possuem menor teor de massa seca que plantas normais e são menos lignificadas estando, assim, mais susceptíveis a perdas de material durante o processo (Hazarika, 2006). Neste trabalho, todavia, não foram observados sinais de hiperidricidade em nenhuma das espécies estudadas, sendo verificado, portanto, uma adequação desses genótipos para o cultivo em meio líquido.

\section{CONCLUSÕES}

De acordo com os parâmetros avaliados neste estudo, é possível concluir que a utilização de meio de cultura MS líquido estático mostra-se como sendo o mais adequado para o cultivo in vitro para todas as espécies de bromélias estudadas sem ocasionar sinais de hiperidricidade.

\section{REFERÊNCIAS}

1. ALVARD, D.; COTE, F.; TEISSON, C. Comparison of methods of liquid medium cultures for banana micropropagation: effect of temporary immersion of explants. Plant Cell, Tissue and Organ Culture, v. 32, n. 1, p. 55-60, 1993.

2. BARBOZA, S. B. S. C.; CALDAS, L. S.; SOUZA, L. A. C. Micropropagação do híbrido PExSC-52 e da cultivar Smooth Cayenne de abacaxizeiro. Pesquisa Agropecuária Brasileira, v. 39, n. 8, p. 725-733, 2004

3. BORGES, N. S. S.; CORREIA, D.; LIMA, R. N. Multiplicação e enraizamento in vitro de brotos de abacaxi ornamental Ananas porteanus Hort Veitch ex C. Koch. Fortaleza: Embrapa Agroindústria Tropical, 2001.5 p.

4. CALDAS, L. S.; HARIDASAN, P.; FERREIRA, M. E. Meios nutritivos. In: TORRES, A. C; CALDAS, L. S. (Eds.). Técnicas e aplicações da cultura de tecidos de plantas. Brasília: ABCTP/EMBRAPA - CNPH, 1990. p. 37-69.

5. CARNEIRO, L. A. et al. In vitro regeneration from leaf explants of Neoregelia cruenta (R. Graham) L. B. Smith, an endemic bromeliad from Eastern Brazil. Plant Cell, Tissue and Organ Culture, v. 55, n. 2, p. 79-83, 1998.

6. CHEN, J.; ZIV, M. The effect of ancymidol on hyperhydricity, regeneration, starch and antioxidant enzymatic activities in liquid-culture Narcissus. Plant Cell Reports, v. 20, n. 1, p. 22-27, 2001.

7. DEBIASI, C. et al. Correlação entre a capacidade proliferativa in vitro e a dominância apical in vivo da bananeira cvs. grand naine e nanicão. Revista Brasileira de Fruticultura, v. 24, n. 3, p. 597-600, 2002

8. DROSTE, A. et al. In vitro culture of Vrisea gigantea and Vrisea philippocoburgii: Two vulnerable bromeliads native to southern Brazil. Brazilian Archives of Biology and Technology, v. 48, n. 5, p. 717-722, 2005. 
MENGARDA, L.H.G. et al. Estado físico do meio de cultura na propagação...

9. ESCALONA, M. et al. Pineapple (Ananas comosus L. Merr) micropropagation in temporary immersion systems. Plant Cell Reports, v. 18, n. 9, p. 743-748, 1999.

10. FEUSER, S.; NODARI, R. O.; GUERRA, M. P. Eficiência comparativa dos sistemas de cultura estacionária e imersão temporária para a micropropagação do abacaxizeiro. Revista Brasileira de Fruticultura, v. 23, n. 1, p. 6-10, 2001

11. FORTES, G. R. L.; PEREIRA, J. E. S. Estabelecimento in vitro da ameixeira cv. América. Revista Brasileira de Fruticultura, v. 23, n. 1, p. 183-185, 2001.

12. GRATTAPAGLIA, D.; MACHADO, M. A. Micropropagação. In: TORRES, A. C., CALDAS, L. S.; BUSO, J. A. (Eds.) Cultura de tecidos e transformação genética de plantas. 1. ed. Brasília: EMBRAPA - SPI/ EMBRAPA - CNPH, 1998. p. 864.

13. HAZARIKA, B. N. Morpho-physiological disorders in in vitro culture of plants. Scientia Horticulturae, v. 108, n. 2, p. 105$120,2006$.

14. KOZAY, T.; KUBOTA, C.; JEONG, B. R.; Environmental control for large-scale production of plants through in vitro techniques. Plant Cell, Tissue and Organ Culture, v. 51, n. 1, p. 49-56, 1997.

15. LEVIN, R. et al. Methods and apparatus for liquid media and semi-automated micropropagation. Acta Horticulturae, v. 447, n. 1, p. 659-664, 1997.

16. LUTHER, H. E. An alphabetical list of bromeliads binomial. 10. ed. Sarasota: The Marie Selby Botanical Gardens, 2006. 119 p.

17. MURASHIGE, G.; SKOOG, F. A revised medium for rapid growth and bio assays with tabaco tissues culture. Physiologia Plantarum, v. 15, n. 3, p. 473-497, 1962.

18. MURASHIGE, T. Plant propagation through Tissue Cultures. Annual Review Plant Physiology, v. 25, p. 135-166, 1974.

19. OLIVEIRA, M. K. T. et al. Propagação in vitro da cultura do abacaxizeiro ornamental (Ananas lucidus Miller). Caatinga, v. 20, n. 3, p. 167-171, 2007.

20. OLIVEIRA, R. R. Importância das bromélias epífitas na ciclagem de nutrientes da Floresta Atlântica. Acta Botânica Brasilica, v. 18, n. 4, p. 793-799, 2004.

21. PEREIRA, J. E. S.; FORTES, G. R. L. Protocolo para produção de material propagativo de batata em meio líquido. Pesquisa Agropecuária Brasileira, v. 38, n. 9, p. 1035-1043, 2003.

22. PRASAD, V. S. S.; GUPTA, S. D. In vitro shoot regeneration of gladiolus in semi-solid agar versus liquid cultures with support systems. Plant Cell, Tissue and Organ Culture, v. 87, n. 3, p. 263-271, 2006.

23. RECH FILHO, A.; DAL VESCO, L. L; GUERRA, M. P. Adventitious shoots from nodule cluster cultures of Vriesea reitzii: an endemic and endangered bromeliad from Atlantic forest. Ciência Rural, v. 39, n. 3, p. 909-912, 2008.

24. REITZ, R. Bromeliaceas e a malária-bromélia endêmica: flora ilustrada de Santa Catarina. Blumenau: Herbário Barbosa Rodrigues, 1983. $856 \mathrm{p}$

25. WANDERLEY, M. G. L. et al. Flora fanerogâmica do Estado de São Paulo. v. 5. São Paulo: Instituto de Botânica, 2007. $476 \mathrm{p}$.

26. ZIV, M. The control of bioreactor environment for plant propagation in liquid culture. Acta Horticulturae, v. 393, n. 1, p. 25-38. 1995

Recebido em 13/03/2009

Aceito em 10/08/2009 